\title{
The Effect of Bio-Oil on High-Temperature Performance of Bio-Oil Recycled Asphalt Binders
}

\author{
Hengcong Zhang*, Jianmin Wu, Zhong Qin and Yin Luo \\ Key Laboratory Special Area Highway Engineering of Ministry of Education, Chang’an University, Xi'an, 710064, China \\ ${ }^{*}$ Corresponding Author: Hengcong Zhang. Email: 2019121171@chd.edu.cn
}

Received: 13 May 2021 Accepted: 18 June 2021

\begin{abstract}
Bio-oil recycled asphalt binders in road engineering can help solve the problem of oil shortage and reduce the environmental pollution and sustainability. This paper investigated the road performance of the aged asphalt binder by adding bio-oil so that the aged asphalt binder could be reused to reach purpose of reuse. The residual soybean oil was selected as rejuvenator and blended with aged asphalt binder at $0 \%, 2 \%, 4 \%$, and $6 \%$, respectively. The results showed that bio-oil increased the penetration of aged asphalt binder, the penetration of bio-oil recycled asphalt binder with a bio-oil content of $6 \%$ reached the standard of $70 \#$ matrix asphalt binder. The addition of bio-oil reduced the viscosity, mixing and compaction temperature of aged asphalt binder. As a common knowledge, bio-oil helps to increase the lightweight components of the aged asphalt binder, which diminishes the high-temperature rutting resistance of bio-oil recycled asphalt binders. The high-temperature deformation resistance of bio-oil recycled asphalt binders had not decreased linearly with the bio-oil dosage. Meanwhile, the hightemperature performance of the bio-oil recycled asphalt binder with a $6 \%$ bio-oil was superior to matrix asphalt binder. Bio-oil increased the light components of the aged asphalt binder, thus reducing the high-temperature rheological properties of bio-oil recycled asphalt binders as the bio-oil dosage increases. The above test results showed that the bio-oil could restore the aged asphalt binder to the initial level to reach the reuse target.
\end{abstract}

\section{KEYWORDS}

Bio-oil; bio-oil recycled asphalt; rotational viscosity; rheological property

\section{Introduction}

As more and more oil resources are exploited, their quantity diminishes. Petroleum asphalt binders are essential materials in the road industry, and how to reuse road asphalt is also a problem to be solved. The most common method is to use a regenerating agent to restore the road performance of aged asphalt binders to achieve the objective of regenerating aged asphalt. Road workers explored and investigated different types of regenerating agents, including bio-oil as a cost-effective regenerating agent $[1,2]$. Gao analyzed the self-healing mechanism of bio-oil regenerated asphalt binders, and the self-healing time of asphalt binders with different aging times was different. Bio-oil enhances the self-recuring ability of aged asphalt binders [3]. Bio-oil could reduce the content of macromolecules and small molecules of aged asphalt binders, improve the dispersion of aging asphalt molecules, and enhance aged asphalt binders' road performance and chemical characteristics. Bio-oil recycled asphalt binders could replace petroleum 
asphalt binders as a renewable resource [4,5]. In terms of anti-aging performance, the bio-oil content of SBS modified bio-oil recycled asphalt binders was lower than 15\%. A modified bio-oil recycled asphalt binder was used to prepare the mixture for road performance research, and bio-oil could enhance the lowtemperature cracking resistance of the asphalt mixture. Bio-oil can be used as a substitute for aromatic oil rejuvenator, and it can be blended in the range of $9 \%-12 \%$. High content of bio-oil would decrease the asphalt mixture's high-temperature performance [6-9]. Preparing the bio-oil recycled asphalt binders was different, and the performance of the bio-oil recycled asphalt binders was also different [10]. In addition, bio-oil recycled asphalt binders had the potential to provide more incredible environmental and economic benefits. The benefits of bio-oil recycled asphalt binders to the environment were analyzed in carbon emission factors [11,12]. Use of waste, cultivated straw as raw material, development of asphalt modified by biomass. Which was environmentally friendly, enhances the low-temperature performance of the basic asphalt to some extent [13]. Organic montmorillonite modified bio-oil recycled asphalt binders, modified bio-oil recycled asphalt binders of sawdust, and polyphosphoric acid-modified bio-oil recycled asphalt binders could also provide good economic benefits [14]. Grease and heavy bio-oil could be used to prepare bio-oil, and the viscosity of bio-oil recycled asphalt binders diminished with the addition of biooil [15-17]. After the aged asphalt was regenerated with heavy bio-oil, the asphalt mixture had a good yield at high temperature, while the yield at low temperature was significantly improved; performance had no significant change [18]. As the bio-oil recycled asphalt content increased, the high-temperature rutting strength, the low-temperature crack strength and water stability, and the fatigue performance of the bio-oil recycled asphalt mixture gradually fallen [19]. The results indicated that the road performance of this bio-oil recycled asphalt mixture had been improved. To sum up, asphalt modified by bio-oil was a research focus for renewable energy. Different types of bio-oil have different road performance.

In this article, organic oil was added to aged asphalt to enhance the plasticity of aged asphalt binder, and the rheological properties of bio-oil recycled asphalt binders were studied. Three indexes tested the conventional properties of bio-oil recycled asphalt binders. The viscosity and high-temperature rheological properties of biooil recycled asphalt binders were determined through rotational viscosity and DSR tests. In combination with the test results, the rheological properties of high-temperature bio-oil recycled asphalt binders were analyzed with the change in bio-oil content. The test results could provide a scientific basis for preparing excellent high-temperature performance and determination of organic oil content.

\section{Experimental Methods}

\subsection{Raw Materials}

In this paper, 70\# matrix asphalt was selected as the raw material, and as described in Table 1, its main indicators meet the requirements of the Chinese asphalt specification [20]. The bio-oil used in this article was a soy oil. Basic properties are presented in Table 2. Soy oil consists of fatty acids and has a high aromatic content; soy oil flows easily at room temperature with good rheological properties; soy oil has the ability to dissolve and disperse asphaltene [19].

\subsection{Preparation of Bio-Oil Modified Asphalt}

In this document, in accordance with the AASHTO specification [21], a rotary film oven was selected to simulate the asphalt binder aging process. As shown in Fig. 2, the relationship between penetration and aging time can be obtained by RTFOT test, and the aging time with penetration of $30 \mathrm{~mm}$ can be determined by curve fitting. Matrix asphalt binder aged for approximately $135 \mathrm{~min}$ could achieve an aged asphalt binder with $30 \mathrm{~mm}$ penetration. At a regeneration temperature of $135^{\circ} \mathrm{C}, 0 \%, 2 \%, 4 \%$, and $6 \%$ of bio-oil was added to the aged asphalt binder and mixed with a rotary shearing machine at a rate of $1600 \mathrm{rad} / \mathrm{min}$, and the mixing time is 15 to $25 \mathrm{~min}$. The specific test process is shown in Fig. 1. The above test process produced four groups of bio-oil recycled asphalt binders. And the 70\# matrix binder was designated MA. 
Table 1: Essential performances of matrix asphalt

\begin{tabular}{llll}
\hline Property & Test results & Technical specification & Test method \\
\hline Penetration index PI & 0.105 & $-1.5 \sim+1.0$ & T0604-2011 \\
Penetration $\left(25^{\circ} \mathrm{C}, 5 \mathrm{~s}, 100 \mathrm{~g}\right)(0.1 \mathrm{~mm})$ & 60.4 & $60 \sim 80$ & $\mathrm{~T} 0604-2011$ \\
Softening point $\left({ }^{\circ} \mathrm{C}\right)$ & 49.8 & $\geq 49$ & $\mathrm{~T} 0606-2011$ \\
Ductility $\left(5 \mathrm{~cm} / \mathrm{min}, 10^{\circ} \mathrm{C}\right)(\mathrm{cm})$ & 27 & $\geq 15$ & $\mathrm{~T} 0605-2011$ \\
Ductility $\left(5 \mathrm{~cm} / \mathrm{min}, 15^{\circ} \mathrm{C}\right)(\mathrm{cm})$ & $>100$ & $\geq 100$ & $\mathrm{~T} 0605-2011$ \\
After RTFOT $\left(163^{\circ} \mathrm{C}, 85 \mathrm{~min}\right)$ & & & $\mathrm{T} 0609-2011$ \\
Mass loss $(\%)$ & -0.078 & $\leq \pm 0.8$ & $\mathrm{~T} 0610-2011$ \\
Residual penetration ratio $(\%)$ & 64 & $\geq 61$ & $\mathrm{~T} 0604-2011$ \\
Residual ductility at $15^{\circ} \mathrm{C}(\mathrm{cm})$ & 21 & $\geq 15$ & $\mathrm{~T} 0605-2011$ \\
\hline
\end{tabular}

Table 2: Basic properties of bio-oil

\begin{tabular}{llll}
\hline Appearance color & Density $(\mathrm{g} / \mathrm{mL})$ & Flash Point $\left({ }^{\circ} \mathrm{C}\right)$ & $60^{\circ} \mathrm{C}$ Viscosity $(\mathrm{mPa} \cdot \mathrm{s})$ \\
\hline Yellowish-brown & 0.947 & 209 & 80 \\
\hline
\end{tabular}

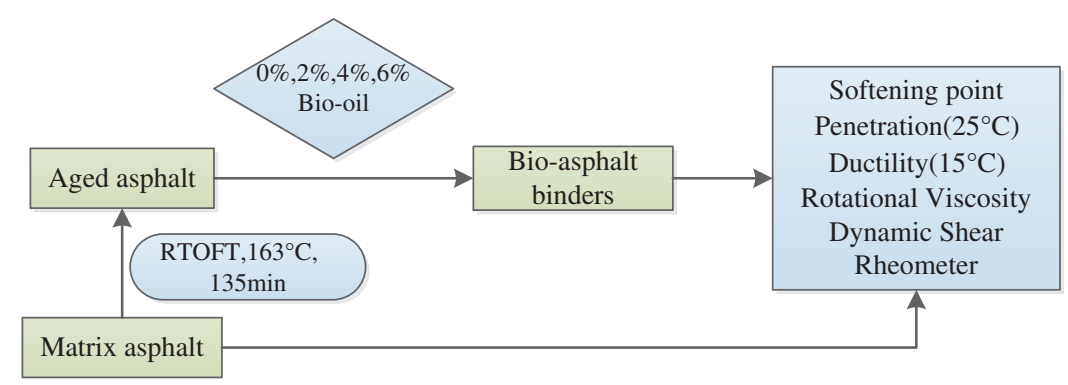

Figure 1: The experimental design map

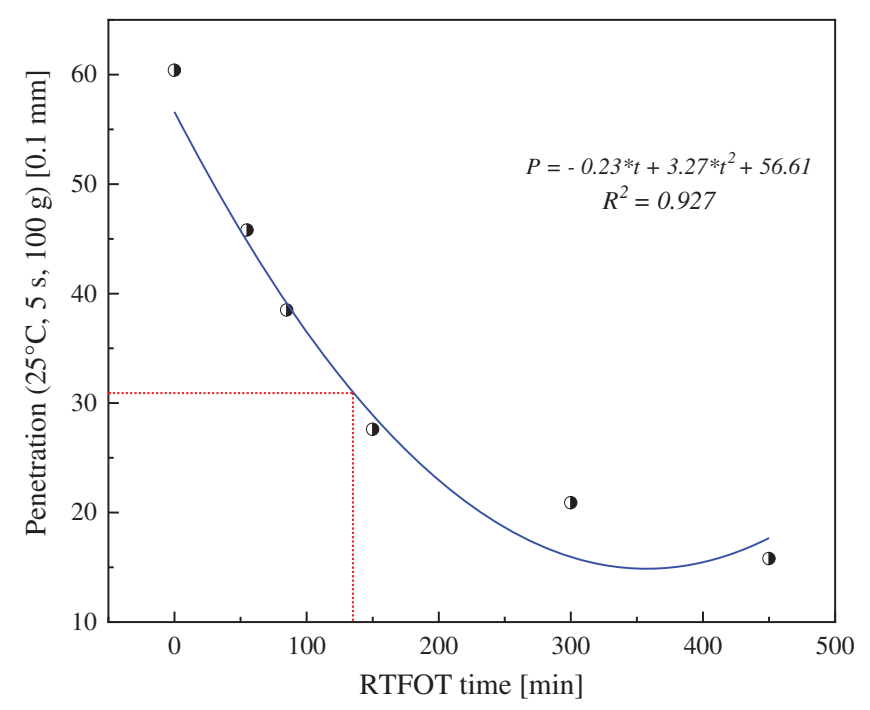

Figure 2: Relationship between penetration and RTPFT time 


\subsection{Conventional Performance and Viscosity Test}

In this section, the conventional properties of various bio-oil recycled asphalt binders were tested following the test procedures of JTG E20-2011. The traditional tests include softening point (JTG E20 T0606-2011), ductility at $15^{\circ} \mathrm{C}$ (JTG E20 T0605-2011), penetration at $25^{\circ} \mathrm{C}$ (JTG E20 T0604-2011). In this paper, a Brookfield viscometer with a temperature control device was selected to determine the viscosity of various bio-oil recycled asphalt binders. The viscosity of $120^{\circ} \mathrm{C}, 135^{\circ} \mathrm{C}, 150^{\circ} \mathrm{C}$, and $165^{\circ} \mathrm{C}$ was measured at a speed of $20 \mathrm{r} / \mathrm{min}$ under AASHTO T 316 [22]. Bio-oil recycled asphalt binders' mixing and compaction temperature could be determined by tracing the viscosity-temperature curve.

\subsection{Rheological Properties Test}

In this article, a dynamic shear rheometer (DSR) was used to assess the rheology properties of bio-oil recycled asphalt binders. The geometrical shape of the plate was chosen with a $25 \mathrm{~mm}$ diameter plate and a $1 \mathrm{~mm}$ release plate [23]. Test results generally analyzed the rheological behavior of bio-oil recycled asphalt binders at different temperatures and angular frequencies. The temperature sweep range was $46^{\circ} \mathrm{C}-82^{\circ} \mathrm{C}$, with $6^{\circ} \mathrm{C}$ as the interval. The test temperature of the frequency sweep was $60^{\circ} \mathrm{C}$, and the angular frequency range was $0.1-100 \mathrm{rad} / \mathrm{s}$. The complex shear modulus, phase angle, and rutting factor derived from the test were used to assess the rheological properties of bio-oil recycled asphalt binders.

\section{Results and Discussion}

\subsection{Traditional Performance Analysis}

The traditional performance results of bio-oil recycled asphalt are shown in Figs. 3a-3c. Basic properties include softening point, ductility $\left(15^{\circ} \mathrm{C}\right)$, and penetration $\left(25^{\circ} \mathrm{C}\right)$. The three major indicators are used as the primary indicators to evaluate the performance of petroleum asphalt, which reflect the high- and lowtemperature road performance of asphalt to a certain extent [24]. As shown in Fig. 3a, the softening point of aged asphalt binder decreases with bio-oil content. Due to the change in bio-oil content is at $2 \%$ intervals, and the reduction in the softening point is low. It can also be seen that the difference in softening point between A3 and MA is slight. To some extent, this indicates that the high-temperature performance of the two asphalt binders is similar. Ductility refers to the total deformation capacity of asphalt under tensile stress at low temperatures, which is used to characterize the plasticity of asphalt. The test results are shown in Fig. 3b. Ductility increases with the increase of bio-oil content. The test results show that $\mathrm{A} 0$ has almost no resistance to cracking at low temperatures, and low-temperature performance is improved after adding bio-oil. Bio-oil improves the low-temperature crack resistance of aged asphalt binders. When the bio-oil content is $4 \%$, the ductility increases the most, and the ductility meets the requirements of the specifications. The dosage of bio-oil must be at least greater than $4 \%$ so that the low-temperature performance of bio-oil recycled asphalt binders can meet the requirements of the specifications. Bio-oil recycled asphalt binders' penetration is depicted in Fig. 3c, reflecting the viscosity of bio-asphalt binders. Bio-oil recycled asphalt binders penetration increases as bio-oil increases, and increase range is even. Depending on the technical classification requirements of the Chinese Asphalt Code, A3 may be used as 70\# matrix asphalt for paving roads. Only when the organic oil exceeds 6\% can bio-oil recycled asphalt binders meet the 70\# matrix asphalt specification requirements. In summary, bio-oil can enhance the low-temperature performance of the aged asphalt binder while reducing its hightemperature performance. To return aged asphalt binder to the matrix asphalt binder standard, the quantity of bio-oil must not be less than $6 \%$. 


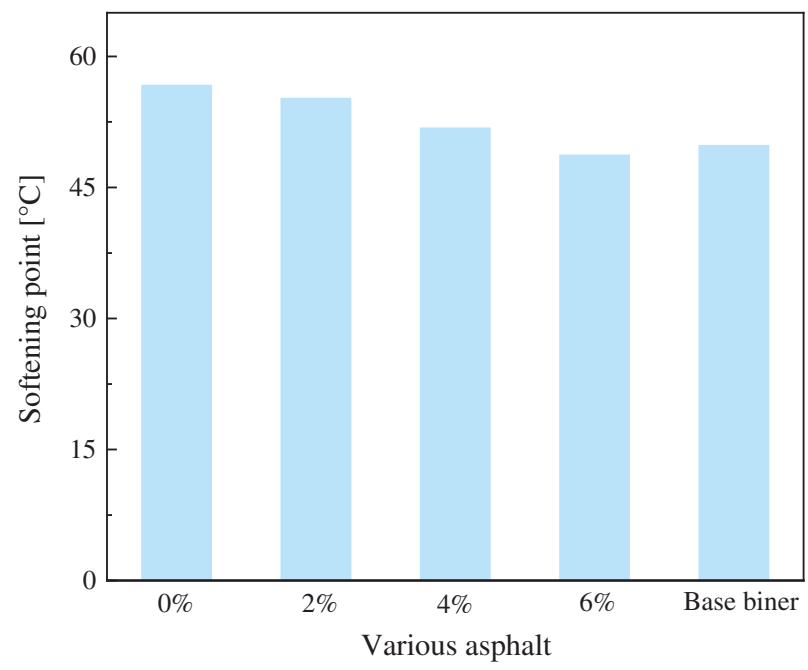

(a)

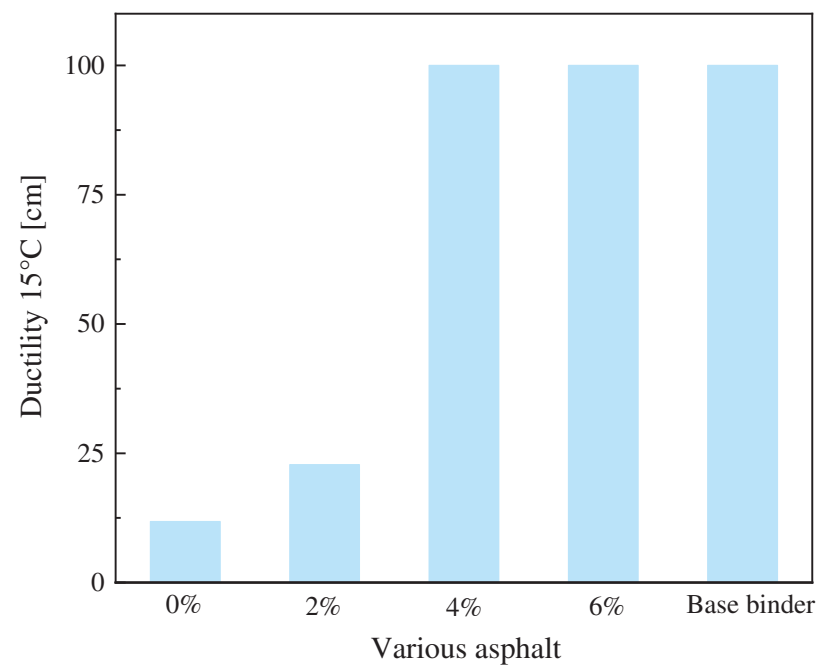

(b)

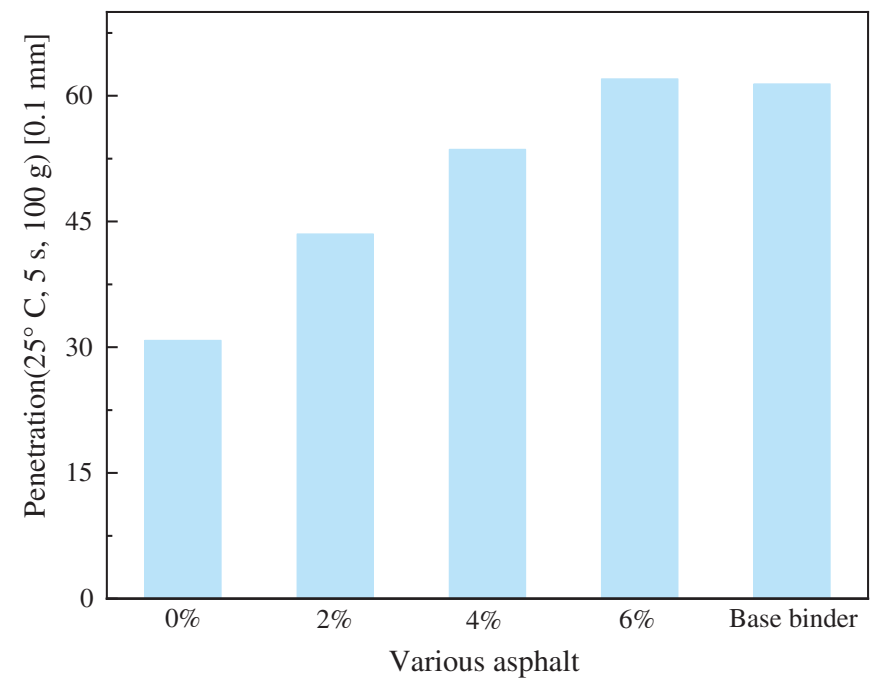

(c)

Figure 3: Conventional performance results

\subsection{Rotational Viscosity Results}

Fig. 4 illustrates the characteristics of different bio-oil recycled asphalt viscosity changes. By drawing the viscosity and temperature in a curve, we analyze the law of the changes in viscosity of the bio-oil recycled asphalt binders, which can also be used to determine the mixing and compaction temperature [25]. Test results show that the viscosity of bio-oil recycled asphalt binders is highly temperature dependent and the viscosity of bio-oil recycled asphalt binders gradually decreases as the temperature increases. The viscosity of bio-oil recycled asphalt binders decreases as the content of bio-oil increases, and the viscosity decrease is relatively uniform. The main reason is that bio-oil increases the light components of aged asphalt, thus reducing the viscosity. By comparing A0 and A3, we can see that bio-oil can significantly reduce the viscosity of aged asphalt binder, making aged asphalt binder reach the regenerating effect. According to JTG E20-2011, the temperature when viscosity is $0.17 \pm 0.02 \mathrm{~Pa} \cdot \mathrm{s}$ taken as the mixing temperature of asphalt mixture. The temperature when the viscosity is $0.28 \pm 0.03 \mathrm{~Pa} \cdot \mathrm{s}$ taken as the 
compaction temperature [20]. The reduction in the viscosity of bio-oil recycled asphalt binders will reduce their construction temperature range. It can be seen in Fig. 4 that the mixing and compaction temperature of bio-oil recycled asphalt binders decrease with the increase of bio-oil. The mixing temperature of $\mathrm{A} 3$ is $145^{\circ} \mathrm{C}-150^{\circ} \mathrm{C}$, and mixing temperature of the matrix asphalt binder is $140^{\circ} \mathrm{C}-145^{\circ} \mathrm{C}$. The mixing temperature of $\mathrm{A} 3$ is greater than that of the matrix asphalt binder. The compaction temperature of the $\mathrm{A} 3$ is also shown to be $6^{\circ} \mathrm{C}$ higher than that of the base asphalt. In conclusion, bio-oil reduces viscosity by improving the viscosity component of aged asphalt binder, contributing to the feasibility of construction.

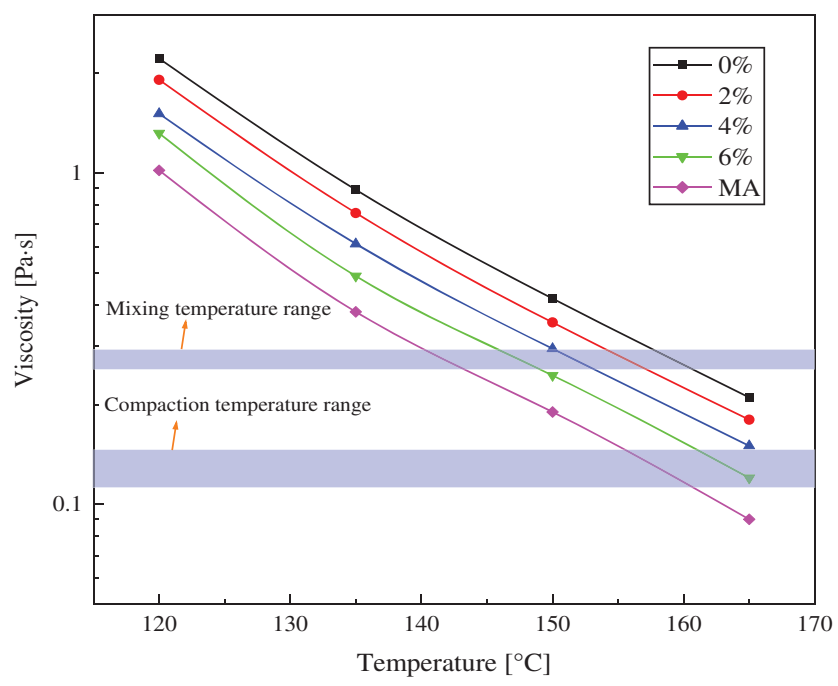

Figure 4: Viscosity values of bio-oil recycled asphalt at different temperatures

\subsection{DSR Results}

\subsubsection{Analysis of Viscoelastic Results}

As a viscoelastic material, asphalt binder is critical to the analysis of its rheological properties. The storage modulus (G'), loss modulus (G'), and rutting factor of the bio-oil recycled asphalt binders may be achieved by DSR test. The storage modulus and the loss modulus characterize the degree of elasticity and the viscosity characteristics of asphalt binders [26]. It can be seen from Fig. 5a that the storage modulus gradually decreases with the increase of temperature and the heavy components in the asphalt decrease with the increase of temperature. Comparing A1, A2, and A3, it can be seen that the storage modulus decreases significantly when the bio-oil content is $2 \%$ and $4 \%$, and the decrease range of A3 is the smallest. This indicates that the modifying effect of bio-oil may be weakened by increased dosage. As the temperature increases, the difference in the storage modulus between the bio-oil recycled asphalt binders becomes increasingly smaller. This indicates that the modifying effect of the bio-oil gradually weakens with the rise in temperature. Fig. 5b shows that the loss modulus also depends greatly on temperature. The loss modulus is larger than the storage modulus, which shows that the bio-oil recycled asphalt binders also have viscous characteristics at high temperatures. The loss modulus also decreases progressively with the increase of bio-oil, and its decreasing range is also different. When the oil content is $2 \%$ and $4 \%$, the reduction range is the most significant. The difference between the loss modulus of A3 and the matrix asphalt is minimal, indicating that the addition of $6 \%$ bio-oil can make the loss modulus of the aged asphalt binder reach the level of the matrix asphalt binder. Comparing Figs. 5a and $5 \mathrm{~b}$ we can see that when the bio-oil content is $6 \%$, the storage modulus and loss modulus of A3 are very small compared to the matrix asphalt binder, which shows that bio-oil has a good effect on the improvement of viscoelastic characteristics of aged asphalt binder. 


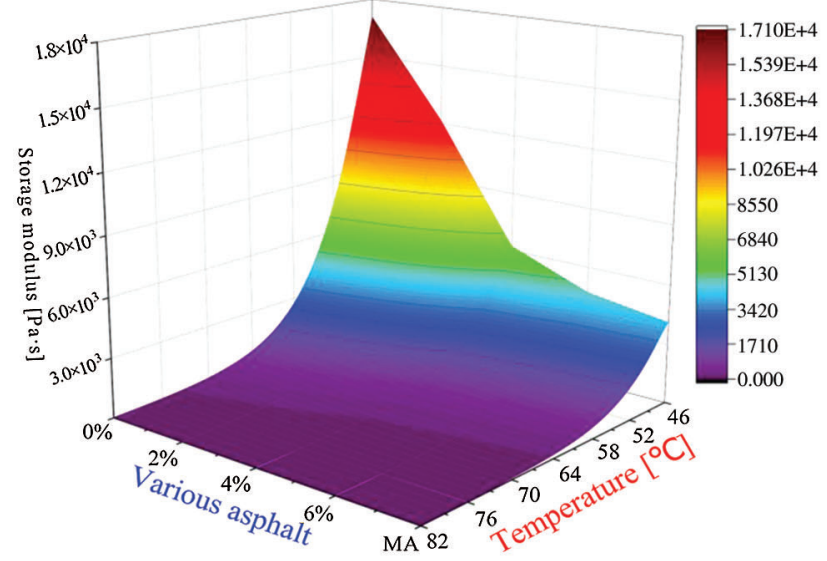

(a)

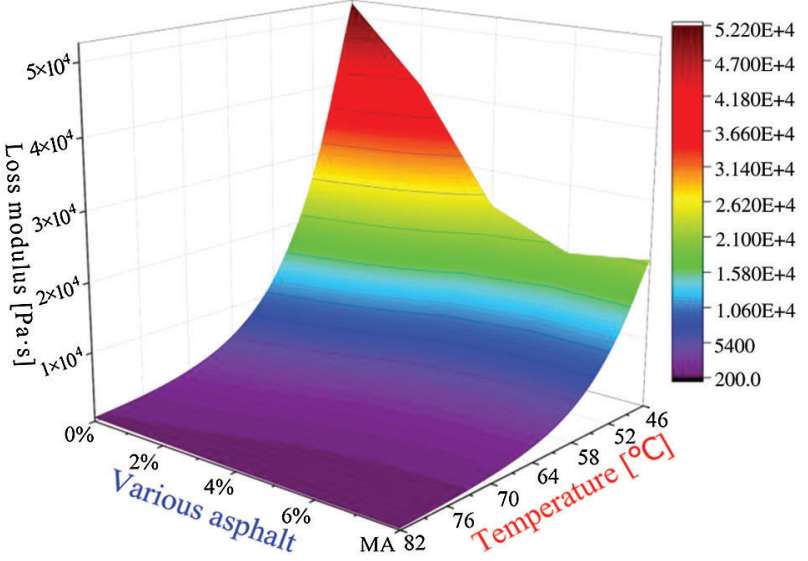

(b)

Figure 5: The relationship between storage and loss modulus and bio-oil recycled asphalt binders (a) Storage modulus (b) Loss modulus

This paper selects the loss factor combined with the storage modulus and loss modulus to analyze the high-temperature rheological properties of bio-oil recycled asphalt binders. The loss factor shall take account of the viscoelastic characteristics of the asphalt. The lower the loss factor, the greater the resilient recovery capacity [27]. Fig. 6a shows that bio-oil increases the loss factor on aged asphalt, and bio-oil recycled asphalt binders become more viscous as the bio-oil dosage increases. Comparing A1, A2, and A3, we can see that the bio-oil recycled asphalt binders loss factor gradually increases as bio-oil dosage. The loss factor of the matrix asphalt binder is always greater than A3, demonstrating that the elastic recovery capability of A3 is greater than matrix asphalt after loading. In summary, bio-oil can reduce the elastic recovering capacity and achieve the goal of regenerating aged asphalt biner by improving the viscosity. As the quantity of bio-oil increased, improving the viscoelasticity of aged asphalt binder decreased. When the oil content is $6 \%$, the plasticity of bio-oil recycled asphalt binders is even lower than that of the matrix asphalt binder. The increase in the quantity of bio-oil may reveal more interesting findings.

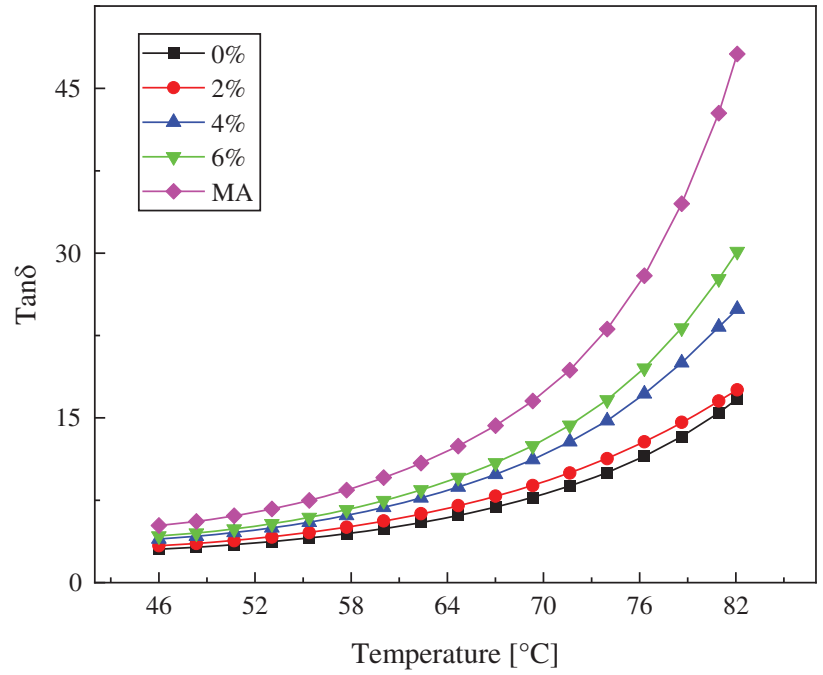

(a)

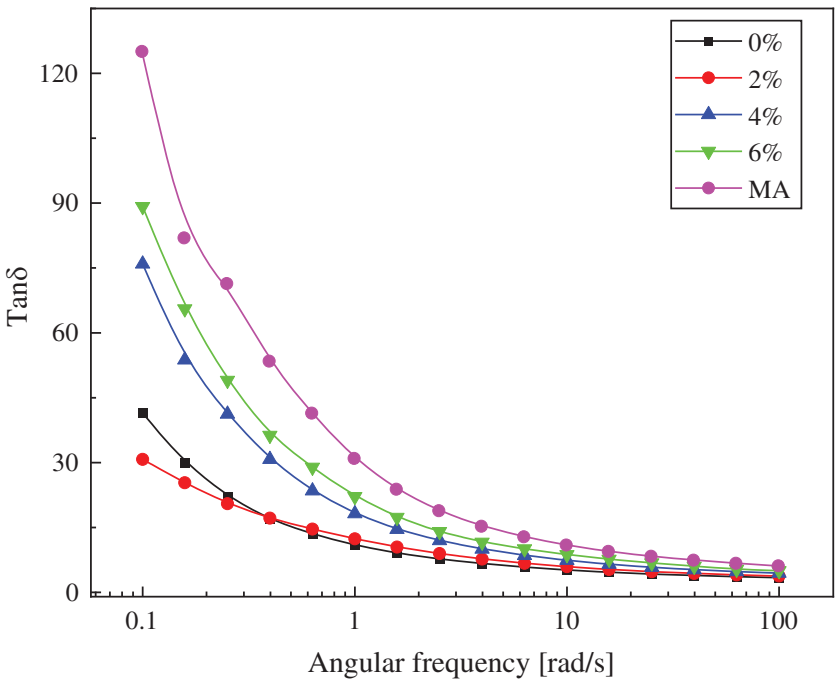

(b)

Figure 6: The relationship between Tan $\delta$ and bio-oil recycled asphalt binders. (a) Temperature sweep (b) Frequency sweep 
The frequency sweep temperature was $60^{\circ} \mathrm{C}$, and the angular frequency range was $0.1-100 \mathrm{rad} / \mathrm{s}$. In combination with the experimental results, the rheological properties of bio-oil recycled asphalt binders were analyzed with different frequencies at $60^{\circ} \mathrm{C}$. Fig. 7 describes the variation of storage modulus and loss modulus of bio-oil recycled asphalt binders at different frequencies. The storage modulus increases as the angular frequency increases as shown in Fig. 6a, indicating that bio-oil recycled asphalt binders are susceptible to deformation under the action of low frequency, thus forming ruts. However, the storage modulus has a smaller increase range than the loss modulus, which is primarily due to the viscosity characteristics of the bio-oil recycled asphalt binders at different angular frequencies, and the proportion of viscous components is relatively large. In addition, the bio-oil can reduce the storage modulus of the aged asphalt binder, and the decreasing amplitude is not apparent. The A3 storage modulus is always superior to the MA. Different conclusions can be found when observing the change in the loss modulus, as shown in Fig. 6b. The downward trend in the loss modulus is almost linear, which indicates that the loss modulus of bio-oil has an apparent law in reducing. It is also evident that the loss modulus varies with the angular frequency fluctuation, and the viscoelastic properties of the bio-oil recycled asphalt binders also depend on the driving speed. Furthermore, analysis of loss factors at different frequencies may further investigate the rheological properties of bio-oil recycled asphalt binders. It can be seen from Fig. $6 \mathrm{~b}$ that the loss factor increases with the increase of the bio-oil content. As indicated above, bio-oil increases the proportion of light components of the aged asphalt binder. Comparing A3 with MA, it can be observed that the rutting strength of $\mathrm{A} 3$ at different angular frequencies is always superior to the matrix asphalt binder. In summary, bio-oil can improve the plasticity of aged asphalt binder by improving their viscous components so that bio-oil recycled asphalt binders can achieve the reuse objective. At the same time, the high-temperature efficiency of the aged asphalt is better than the original level.

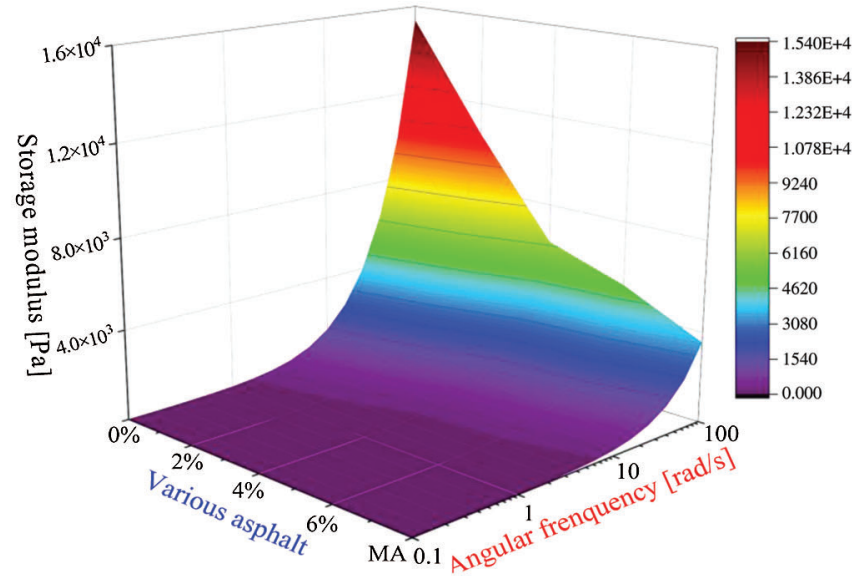

(a)

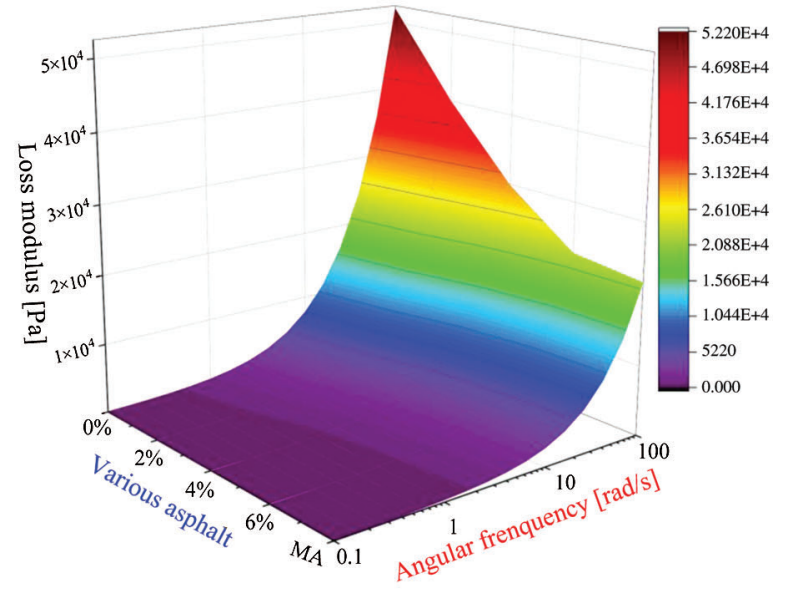

(b)

Figure 7: The relationship between storage modulus and loss modulus and bio-oil recycled asphalt binders (a) Storage modulus, (b) Loss modulus

\subsubsection{Rutting Factor Analysis}

The central damage of asphalt pavement is rutting, and the main reason is that the asphalt mixture is too soft. It is necessary to evaluate the high-temperature performance of asphalt [28]. Fatigue factor $\mathrm{G}^{*} \sin \delta$ and rutting factor $\mathrm{G}^{*} / \sin \delta$ of bio-oil recycled asphalt binders can be obtained by temperature sweep and frequency sweep. The rutting factor and the fatigue factor can characterize the high-temperature rutting capacity of the asphalt [29]. Fig. 8 shows that the fatigue factor for bio-oil recycled asphalt binders decreases as the temperature rises. This demonstrates that the high-temperature fatigue strength of the 
bio-oil recycled asphalt binders declines with the temperature. In addition, the fatigue factor decreases as the bio-oil dosage. The main reason is that the bio-oil increases the viscosity of the aged asphalt, leading to the aged asphalt softening. With the increase in the dosage of bio-oil, the decrease in the fatigue factor progressively decreases. When the amount of bio-oil is $6 \%$ fatigue factor drop is the most significant and fatigue factor of bio-oil recycled asphalt binders is identical to matrix asphalt. This indicates that the high temperature performance of aged asphalt can be restored to the original level by adding $6 \%$ bio-oil. It is feasible to reduce the high temperature performance of aged asphalt with bio-oil as regenerative agent. In conclusion, the above results indicate that when bio-oil improves the plasticity of aged asphalt, it also reduces performance at high temperatures.

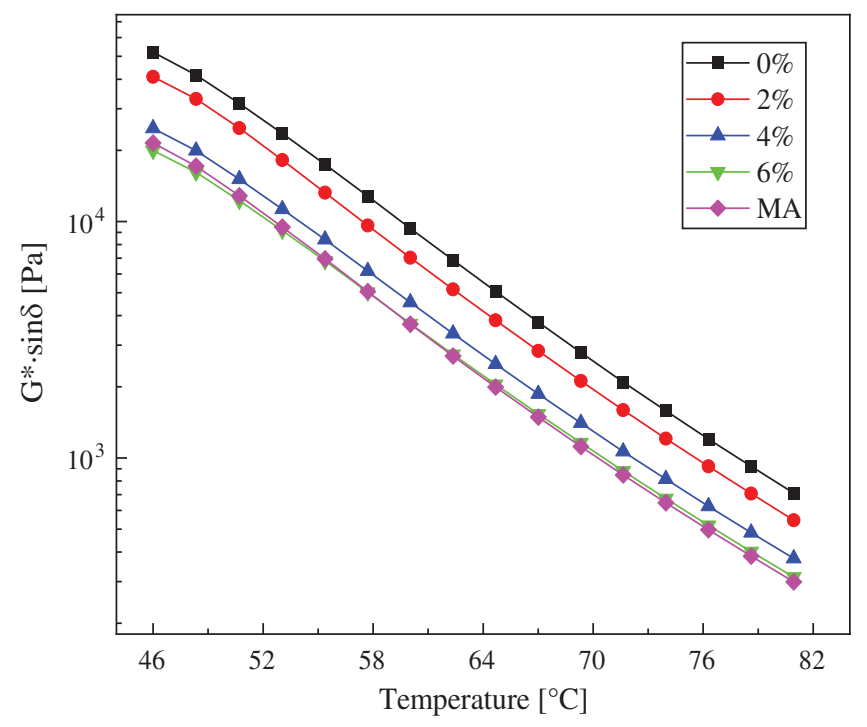

Figure 8: The fatigue factor and temperature

Fig. 9 depicts the increasingly frequent change in the rutting factor of bio-oil recycled asphalt binders. The rutting factor can characterize the high-temperature anti-rutting capability of the bio-oil recycled asphalt binders. It can be seen from the test results that the rutting factor is lower at low frequencies, indicating that the anti-rutting ability of bio-oil recycled asphalt binders under low-frequency conditions is weak, and rutting is easy to form. Bio-oil increases the viscous properties of aged asphalt and weakens the anti-rutting performance of aged asphalt at different frequencies. At the same frequency, the rutting factor decreases with the increase of bio-oil dosage, which is similar to the above conclusion that bio-oil helps to reduce the high temperature performance of aged asphalt. Fig. 9 shows that the rutting factor of A3 is greater than that of matrix asphalt at different frequencies. However, the resistance to deformation of A3 with temperature fluctuations is similar to matrix asphalt. The high-temperature performance of A3 is superior to that of matrix asphalt. Same with the above conclusions, the modifying effect of bio-oil decreases with the increase of bio-oil dosage. Bio-oil improves the plasticity of aged asphalt by reducing the hightemperature deformation resistance of aged asphalt. But this method enables aged asphalt to regenerate. Frequency scanning of bio-oil recycled asphalts binders at different temperatures may yield new findings, and further experimental studies are needed.

\subsubsection{Temperature Sensitivity Analysis}

Bio-oil recycled asphalt binders will change differently depending on temperature fluctuations. In this paper, Ln G*/sin-Ln T is selected for linear fitting; the fitting results are shown in Fig. 10. 


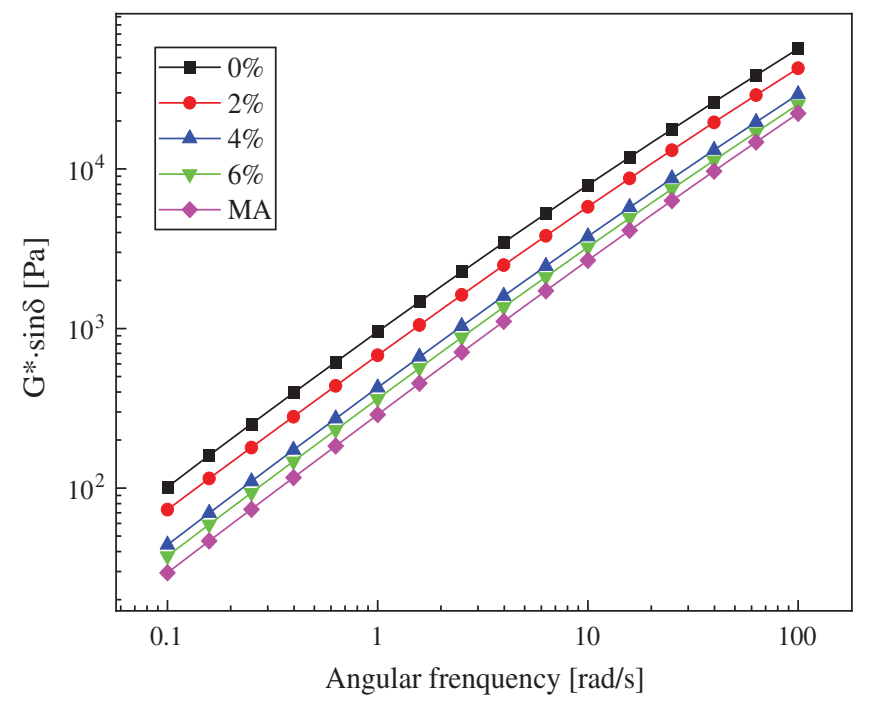

Figure 9: The rutting factor and angular frequency

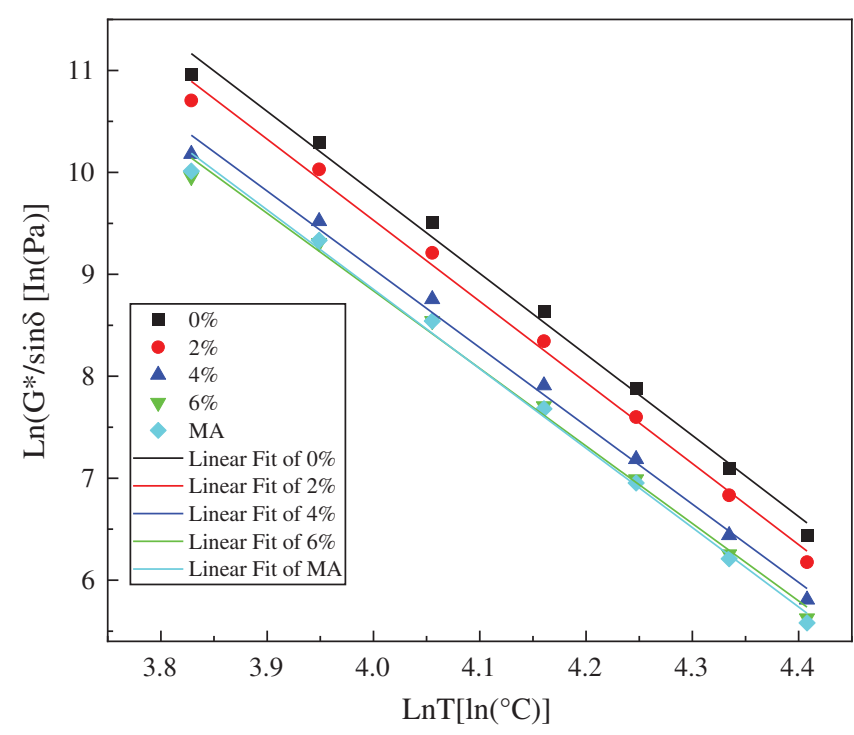

Figure 10: $\operatorname{Ln}\left(\mathrm{G}^{*} / \sin \delta\right)-\mathrm{LnT}$ linear regression

$\mathrm{G}^{*} / \sin -\mathrm{Ln} \mathrm{T}$ is selected for linear fitting; the fitting results are shown in Fig. 10. To better analyze the fitting results, the fitting data are shown in Table 3. We can see the result of fitting that $\mathrm{R}^{2}$ is close to 1 , which shows that the accuracy of the result of the linear adjustment is relatively high [30]. The straight-line slope is used to characterize the temperature sensitivity of the bio-oil recycled asphalt binders. The lower the absolute value of the slope, the less temperature-sensitive of bio-oil recycled asphalt binders. An interesting result can be observed from the slope value, as the temperature sensitivity of the bio-oil recycled asphalt binders increases with the bio-oil dosage. The results show that bio-oil recycled asphalt binders will produce more changes with temperature fluctuations, making the plasticity of bio-oil recycled asphalt binders better than the aged asphalt. It is interesting to note that the temperature sensitivity of A3 is not significantly different from the original level. By comparing $\mathrm{A} 1, \mathrm{~A} 2$, and $\mathrm{A} 3$, it is possible to conclude that temperature sensitivity increases by $0.0824,0.0635,0.0313$, respectively. A similar conclusion can 
be drawn from the temperature sensitivity variation characteristics. The effect of bio-oil to enhance the plasticity of aged asphalt decreases as dosage increases. In summary, bio-oil helps improve the plasticity of aged asphalt by weakening its high temperature properties. However, the change of the high temperature performances of the four bio-oil recycled asphalt binders after RTFOT needs further verification and analysis.

Table 3: Linear fitting results of bio-oil recycled asphalt binders temperature sweep

\begin{tabular}{llll}
\hline Asphalt type & $|\mathrm{A}|$ & $\mathrm{B}$ & $\mathrm{R}^{2}$ \\
\hline $0 \%$ & 7.6724 & 41.559 & 0.99285 \\
$2 \%$ & 7.7548 & 41.322 & 0.99409 \\
$4 \%$ & 7.8183 & 39.734 & 0.99365 \\
$6 \%$ & 7.8496 & 39.235 & 0.99371 \\
MA & 7.8541 & 39.990 & 0.99473 \\
\hline
\end{tabular}

\section{Conclusion}

In this study, four bio-oil recycled asphalt binders were prepared by physical blending. Through conventional performance tests, rotational viscosity and dynamic rheometer shear investigated conventional performance, construction feasibility, high-temperature flange resistance, and temperature sensitivity of various bio-oil recycled asphalt binders. Changes in road performance in bio-oil recycled asphalt binders are examined. The conclusions from the experimental data can be summarized as follows:

1. As a light component, bio-oil was mixed into aged asphalt binder to improve their low-temperature performance by weakening the high-temperature performance. When the bio-oil dosage is $6 \%$, the softening point of the aged asphalt is reduced by $16.4 \%$, but the low-temperature ductility is increased by 8.5 times. In addition, the mixing and compaction temperature decreases with the bio-oil content.

2. Bio-oil enhances the plasticity of aged asphalt by increase the loss modulus relatively. Loss factor analysis can be obtained that storage modulus decreases more than the loss modulus, which causes the viscous component of bio-oil recycled asphalt binders to increase with the bio-oil dosage. A comparison of A3 and MA shows that aged asphalt binder may regain its plasticity when the bio-oil content is $6 \%$. The bio-oil level should be maintained at about $6 \%$.

3. As expected, anti-rutting performance of aged asphalt decreases with the bio-oil content, as does the temperature sensitivity. The effect of bio-oil in weakening the high-temperature performance of aged asphalt decreases as its content increases. To sum up, bio-oil can achieve the goal of regenerating aged asphalt binder, and the amount of bio-oil should be about $6 \%$.

Acknowledgement: Thanks to Dr. Wu, School of Highway, Chang'an University, for financial support.

Funding Statement: The authors received no specific funding for this study.

Conflicts of Interest: The authors states that there is no conflict of interest with this article. 


\section{References}

1. Leng, L., Zhang, W., Peng, H., Li, H., Jiang, S. et al. (2020). Nitrogen in bio-oil produced from hydrothermal liquefaction of biomass: A review. Chemical Engineering Journal, 401(1), 126030. DOI 10.1016/j. cej.2020.126030.

2. Leng, L., Li, H., Yuan, X., Zhou, W., Huang, H. (2018). Bio-oil upgrading by emulsification/microemulsification: A review. Energy, 161(126), 214-232. DOI 10.1016/j.energy.2018.07.117.

3. Gao, X., Liu, Z. (2019). Self-healing mechanism analysis of bio-oil recycled asphalt. China Journal of Highway and Transport, 32(4), 235-242. DOI 10.19721/j.cnki.1001-7372.2019.04.021.

4. Dong, Z., Zhou, T., Luan, H., Yang, C., Wang, P. et al. (2019). Preparation and mechanism of SBS/ rubber powder composite modified SH-type mixture asphalt. China Journal of Highway and Transport, 32(4), 215-225. DOI 10.19721/j.cnki.1001-7372.2019.04.019.

5. Al-Sabaeei, A. M., Napiah, M. B., Sutanto, M. H. (2021). Determination of rheological properties of bio-asphalt binders through experimental and multilayer feed-forward neural network methods. Ain Shams Engineering Journal, 201(1), 268. DOI 10.1016/j.asej.2021.04.003.

6. Li, J. (2020). Study on the properties of cement-based bio-asphalt mixtures. Shaanxi Transportation Science and Technology, 2, 9-13. DOI cnki sun: sxjt.0.2020-02-004.

7. Modupe, A. E., Atoyebi, O. D., Oluwatuyi, O. E., Aladegboye, O. J., Busari, A. A. (2018). Dataset of mechanical, marshall and rheological properties of crumb rubber-bio-oil modified hot mix asphalt for sustainable pavement works. Construction and Building Materials, 21(4), 63-70. DOI 10.1016/j.dib.2018.09.080.

8. Uchoa, A. F. J., da Silva Rocha, W. (2021). Bio-based palm oil as an additive for asphalt binder: Chemical characterization and rheological properties. Construction and Building Materials, 285(9), 950-618. DOI 10.1016/j.conbuildmat.2021.122883.

9. Yong, L., Wang, H., Chen, X., Yang, X., You, Z. (2018). Shear property, high-temperature rheological performance and low-temperature flexibility of asphalt mastics modified with bio-oil. Construction and Building Materials, 174(1), 30-37, 950-618. DOI 10.1016/j.conbuildmat.2018.04.094.

10. Zou, X., Hou, H. (2020). Quantitative analysis of carbon emission and economic benefits of bio-bitumen. Chinese and Foreign Highway, 4, 323-326. DOI 10.14048/j.issn.1671-2579.2020.04.068.

11. Zhao, J., Li, L., Li, Z. (2020). Preparation and properties of bio-oil /SBS modified asphalt. Chemical New Materials, 5, 246-250. DOI 10.19817/j.cnki.issn1006-3536.2020.05.056.

12. Li, Z., Li, P., Liang, Y., Hu, B. (2016). A review of the development and research status of bio-bitumen. Highway Traffic Science and Technology (Application Technology Edition), 7, 95-97. DOI cnki:sun:gljj.0.2016-07-038.

13. Ding, Z., Zhao, J., Jiang, X., Li, P. (2020). Preparation technology and performance analysis of bio-asphalt based on straw liquefaction. Journal of Wuhan University of Technology (Transportation Science and Engineering), 1, 6-10. DOI cnki:sun:jtkj.0.2020-01-002.

14. Feng, X., Zhang, Y., Wei, H., Dai, Y. (2021). Rheological properties of organic montmorillonite modified bitumen. Journal of Railway Science and Engineering, 3, 687-694. DOI 10.19713/j.cnki431423/u.t20200447.

15. Zhou, S., Wu, H., Liu, Y. (2019). Study on the properties of polyphosphoric acid modified bitumen and its mixture. Contemporary Chemical Industry, 6, 1205-1208+1212. DOI 10.13840/j.cnki.cn21-1457/tq.2019.06.024.

16. Cao, X., Li, L., Liu, Y., Shan, B. (2019). Preparation of bio-heavy oil and bio-asphalt by thermal liquefaction of wood dust. Application of Chemical, 6, 1374-1377+1381. DOI 10.16581/j.cnki.1671-3206.20190523.021.1374.

17. Cao, X., Liu, Y., Cao, X., Liu, P., Miao, C. (2019). Preparation and properties of biomass heavy oil and biobitumen. Journal of Chang'an University (Natural Science Edition), 3, 27-35. DOI 10.19721/j.cnki.16718879.2019.03.004.

18. Zhang, Z. (2020). Study on the application performance of bio-bitumen recycled asphalt mixture. The Western Traffic Science and Technology, 11, 101-103. DOI 10.13282/j.carolcarrollnkiwccst.2020.11.027.

19. Tang, L. (2018). Study on properties of biologically modified asphalt and its mixtures. North Traffic, 7, 143-147. DOI 10.15996/j.carolcarrollnkibfjt.2018.07.039. 
20. Chinese Ministry of Transport Highway Research Institute (2011). Standard test methods of bitumen and bituminous mixtures for highway engineering. Beijing: China Communications Press.

21. AASHTO (2009). Standard method of test for effect of heat and air on a moving film of asphalt binder (rolling thinfilm oven test). Washington DC: American Association of State Highway and Transportation Officials.

22. AASHTO (2013). Standard method of test for viscosity determination of asphalt binder using rotational viscometer. Washington DC: American Association of State Highway and Transportation Officials.

23. AASHTO (2013). Standard method of test for determining the rheological properties of asphalt binder using a Dynamic Shear Rheometer (DSR) (T 315-12). Washington DC: American Association of State Highway and Transportation Officials.

24. Zhu, H., Wei, M., Wan, Y., Xiang, H., Yang, Y. (2018). Experimental study on physical properties of bio-heavy oil recycled asphalt. Journal of Chongqing Jiaotong University (Natural Science), 8, 23-28. DOI cnki:sun: cqjt.0.2018-08-005.

25. Yan, K. Z., Chen, J. H., You, L. Y., Tian, S. (2020). Characteristics of compound asphalt modified by waste tire rubber (WTR) and ethylene vinyl acetate (EVA): Conventional, rheological, and microstructural properties. Journal of Cleaner Production, 258, 959-6526. DOI 10.1016/j.jclepro.2020.120732.

26. Lei, Y., Wang, H., Ellie, H., Fini, E. H., You, Z. et al. (2018). Evaluation of the effect of bio-oil on the hightemperature performance of rubber modified asphalt. Construction and Building Materials, 191, 692-701. DOI 10.1016/j.conbuildmat.2018.10.064.

27. Zhao, L., Zha, R., Chen, Q., Zhang, X. (2018). Rheological properties of SBS modified light-color asphalt binder. Journal of East China University of Science and Technology (Natural Science Edition), 1, 21-27. DOI 10.14135/j. cnki.1006-3080.20170315004.

28. Nayak, P., Sahoo, U. C. (2017). A rheological study on aged binder rejuvenated with Pongamia oil and Composite castor oil. International Journal of Pavement Engineering, 18(7), 595-607. DOI 10.1080/10298436.2015.1103851.

29. Al-Saffar, Z. H., Yaacob, H., Satar, M. K. I. M., Saleem, M. K., Jaya, R. P. et al. (2020). Evaluating the chemical and rheological attributes of aged asphalt: Synergistic effects of maltene and waste engine oil rejuvenators. Arabian Journal For Science and Engineer, 45, 8685-8697. DOI 10.1007/s13369-020-04842-7.

30. Zhang, R., Wang, H., Gao, J., You, Z. (2017). High temperature performance of SBS modified bio-asphalt. Construction and Building Materials, 144, 99-105. DOI 10.1016/j.conbuildmat.2017.03.103. 